\title{
Ficoll-Hypaque Method
}

National Cancer Institute

\section{Source}

National Cancer Institute. Ficoll-Hypaque Method. NCI Thesaurus. Code C129690.

A centrifugation procedure that utilizes a density-gradient medium to separate

mononuclear and polymorphonuclear leukocytes from other formed elements in the blood. 